\title{
DESAIN SARANA BAWA DAN PENYIMPANAN PERALATAN PRAKTIKUM PRIBADI BAGI MAHASISWA JURUSAN TEKNIK KIMIA POLITEKNIK NEGERI SAMARINDA
}

\author{
Dita Andansari ${ }^{1}$ \\ ${ }^{1}$ Staf Pengajar Program Studi Desain Produk, Jurusan Desain \\ Politeknik Negeri Samarinda \\ Nur Maulida Agusnar ${ }^{2}$ \\ ${ }^{2}$ Mahasiswa Program Studi Desain Produk, Jurusan Desain \\ Politeknik Negeri Samarinda
}

\begin{abstract}
ABSTRAK
Praktikum merupakan salah satu metode pembelajaran yang digunakan pada sistem belajar mengajar di lembaga-lembaga pendidikan. Politeknik Negeri Samarinda sebagai salah satu lembaga pendidikan tinggi menerapkan metode praktikum dalam proses belajar mengajar. Teknik kimia yang merupakan jurusan teknik terapan memiliki serangkaian praktikum untuk dilakukan demi menunjang proses belajar mengajar. Pada kegiatan praktikum Jurusan Teknik Kimia, mahasiswa jurusan tersebut mewajibkan setiap mahasiswanya untuk memiliki peralatan praktikum pribadi guna menunjang kebutuhan setiap mahasiswa dalam melaksanakan praktikum. Mahasiswa-mahasiswa jurusan Teknik Kimia Politeknik Negeri Samarinda membawa dan menyimpan peralatan praktikum pribadinya pada sebuah kotak sepatu yang dilapisi kertas sampul. Penggunaan kotak sepatu sebagai sarana bawa dan penyimpanan membuat peralatan praktikum mudah rusak dan tidak terkonfigurasi secara baik. Tujuan yang ingin dicapai dalam perancangan produk ini adalah membuat produk berupa sarana bawa dan penyimpanan bagi peralatan praktikum pribadi mahasiswa jurusan Teknik Kimia Politeknik Negeri Samarinda yang mampu menekan kemungkinan peralatan praktikum mudah rusak dan mampu membuat peralatan praktikum terkonfigurasi secara baik. Dengan berbagai metode perencanaan dan perancangan yang diantaranya adalah : pengumpulan data, konsep desain, alternatif desain, hingga mencapai desain akhir, diharapkan usulan desain ini dapat memberi masukan bagi pihak-pihak terkait untuk dapat melengkapi halhal yang belum tercapai pada sarana bawa dan penyimpanan bagi peralatan praktikum pribadi mahasiswa jurusan Teknik Kimia Politeknik Negeri Samarinda.
\end{abstract}

Kata kunci : praktikum, sarana bawa, sarana penyimpanan, teknik kimia 
Vol. 2, No. 2, April 2015

\begin{abstract}
Practicum is one of the teaching methods used in teaching and learning system in educational institutions. Polytechnic State of Samarinda as one of the higher education institutions apply practical methods in learning process. Chemical engineering department have a following practicum to be done in order to support the learning process. At the chemical engineering department practicum activities, students of the department requires each student to have a personal lab equipment to support the needs of every student in practicum. Students in Chemical Engineering department in Polytechnic State of Samarinda carrying and storing their personal lab equipment in a shoe box lined paper cover. The use of a shoe box as carrying and storing facilities make a personal lab equipment can be easily demaged and is not configured properly. The goal in the design of this product is to make products such as carrying and storing facilities for personal lab equipment Chemical Engineering students were able to suppress the possibility of lab equipment can be easily demaged and are able to make the lab equipment configured properly. With a various methods of scheming and design such as data collection, design concept, design alternative, until achieve a final design, this design proposal can be expected to give an input for the related parties to complete a things which have not been achieved in carrying and storing for personal lab equipment for Chemical Engineering department of Polytechnic State of Samarinda students
\end{abstract}

Keywords : practicum, carrying facility, storing facility, chemical engineering

\title{
I. Pendahuluan
}

Praktikum merupakan salah satu penyimpanannya. Produk sarana bawa dan metode yang diterapkan dalam pembelajaran guna mencapai tujuan-tujuan pendidikan. Praktikum telah menjadi komponen pembelajaran secara formal. "Praktikum mampu meningkatkan motivasi belajar, mengembangkan keterampilan-keterampilan dasar dalam eksperimen, dan menjadi wahana belajar pendekatan ilmiah serta menunjang pemahaman materi pelajaran” (Rustaman 2011)

Dalam kegiatan praktikum pada umumnya terdapat peralatan penunjang yang diperlukan. Untuk meletakkan peralatan tersebut telah terdapat sarana bawa dan penyimpanan tersebut berupa tas ataupun toolskit. Toolskit peralatan praktikum dipasaran berupa koper dalam ukuran kecil dan berbahan keras seperti alumunium dan plastik.

Politeknik Negeri Samarinda sebagai Lembaga Pendidikan, menerapkan metode praktikum dalam kegiatan pembelajaran. Jurusan Teknik Kimia memiliki mata kuliah yang mengharuskan mahasiswa melaksanakan praktikum di laboraturium. Kegiatan praktikum tersebut mengharuskan setiap mahasiswa untuk memiliki peralatan pribadi yang harus dibawa saat 
Dita Andansari, Nur Maulida Agusnar, Desain Sarana Bawa Dan Penyimpanan Peralatan Praktikum Pribadi Bagi Mahasiswa Jurusan Teknik Kimia Politeknik Negeri Samarinda

melaksanakan kegiatan. Sebagai sarana bawa dan penyimpanannya, mahasiswa jurusan Teknik Kimia sering menggunakan kotak sepatu. Penggunaan kotak sepatu sebagai sarana bawa dan penyimpanan menyulitkan pengguna dalam membawa serta meletakkan peralatan secara teratur. Peletakkan peralatan yang tidak teratur dapat meningkatkan resiko rusaknya peralatan. Selain itu, kotak sepatu yang memang tidak dirancang sebagai sarana bawa membuat penggunaannya sebagai sarana bawa peralatan praktikum ini 'kurang ergonomis dan estetis sehingga tidak memenuhi atribut perbaikan produk' (Saufik dan Siswiyanti, 2013)

Di pasaran belum banyak ditemukan sarana bawa dan penyimpanan peralatan praktikum yang mampu menjadi produk sarana bawa dan penyimpanan yang kuat. Selain itu, toolskit berupa koper berukuran kecil yang telah ada di pasaran memiliki tampilan visual yang kurang sesuai dengan style serta karakteristik mahasiswa. Dengan demikian, sarana bawa dan penyimpanan peralatan praktikum pribadi untuk mahasiswa jurusan teknik kimia Politeknik Negeri samarinda sangat dibutuhkan dan hal itu menjadi dasar perancangan produk ini.

\section{Metode Penelitian}

Dalam proses desain ini dilkukan metode penelitian agar tahap tahap yang dilakukan dapat etrancana dan didapatkan hasil yang tersusun bagi. Metode tersebut yaitu:
1. Obsevasi. Observasi dilakukan untuk menemukan permasalahanpermasalahan yang ada di lingkungan sekitar dan memilih permasalahan apa yang akan diselesaikan sebagai tujuan akhir dari perancangan produk. Setelah observasi dilakukan, ditemukan masalah mengenai sarana bawa peralatan praktikum bagi mahasiswa teknik kimia Politeknik Negeri Samarinda. Sebagai lanjutan, dilakukanlah pengumpulan data dengan metode wawancara dan kuisioner guna mendapat informasi mengenai keadaan lapangan dan kebutuhan pengguna yang dilakukan dengan mengambil sampel dari populasi pengguna yaitu mahasiswa jurusan teknik kimia.

2. Perumusan masalah. Setelah ditemukan permasalahan yang membutuhkan penyelesaian dan data dari wawancara serta kuisioner, di dapatkan hasil berupa keadaan lapangan serta kebutuhan para pengguna yang harus dipenuhi. Dari hal tersebut dirumuskanlah permasalahanpermasalahan yang membutuhkan solusi berupa penyelesaian yang akan dituangkan dalam perancangan produk sarana bawa dan penyimpanan untuk peralatan praktikum pribadi mahasiwa.

3. Studi Pustaka. Studi pustaka dilakukan dengan mengumpulkan data dari berbagai sumber literatur atau jurnal ilmiah guna menemukan data serta informasi terkait hal yang akan dibahas serta produk yang akan dibuat. Dalam perancangan produk ini, studi pustaka 
Vol. 2, No. 2, April 2015

dilakukan terhadap berbagai informasi, teori, klasifikasi, trend mengenai tas dan sarana bawa.

4. Analisis data. Analisis dilakukan terhadap permasalahan, data dan informasi yang telah terkumpul. Analisa dilakukan dalam perancangan produk guna memberikan petunjuk mengenai produk seperti apa yang dibutuhkan.

5. Alternatif desain. Alternatif desain dibuat sebagai pilihan solusi untuk masalah desain produk yang akan dirancang dan dibuat berupa prototype sebagai hasil akhir. Alternatif desain akan dianalisis kelebihan dan kekurangannya hingga terpilih satu desain yang dinilai mampu menjadi penyelesaian permasalahan serta mampu memenuhi kebutuhan mahasiswa sebagai pengguna.

6. Pengembangan desain terpilih. Desain yang telah terpilih dari alternatif akan dikembangkan hingga mampu menjadi produk yang maksimal. Pengembangannya dapat dalam segi bentuk, warna, sistem ataupun elemen lainnya sesuai analisis yang telah dilakukan. Perkembangan terhadap desain terpilih hanya mengubah sebagian kecil dari desain awal karena perkembangan dilakukan sebagai penyempurna produk agar maksimal dalam menyelesaikan masalah dan memenuhi kebutuhan pengguna.

7. Modelling. Model merupakan rancangan produk yang dibuat sebagai gambaran awal. Model biasanya dibuat dengan skala tertentu. Untuk produk ini, model dibuat dengan skala $1: 1$ sesuai dengan dimensi asli karena dimensi asli yang tidak terlalu besar. Model dibuat dengan material kain menyerupai material pada produk asli sehingga mampu memberikan gambaran awal produk dengan cukup jelas.

\section{Pembuatan gambar dan prototype.}

Gambar yang dibuat sebelum pembuatan prototype adalah gambar fungsional dan gambar teknik produk yang mampu menjelaskan bagaimana spesifikasi serta penggunaan produk. Setelah dibuat gambar fungsional dibuatlah prototype yang merupakan produk skala $1: 1$ dan fungsional. Pembuatan protype disesuaikan dengan desain terpilih yang telah dikembangkan berdasarkan analisis-analisis yang telah dilakukan.

\section{Pembahasan}

Analisis aktivitas dan kebutuhan dilakukan untuk mengetahui aktivitas yang dilakukan dan kebutuhan yang harus dipenuhi. Dari analisis aktivitas dan kebutuhan hasil analisa yang telah, maka dapat disimpulkan mengenai komponen-komponen apa saja yang harus ada pada produk. Adapun komponen-komponen tersebut adalah sebagai berikut: (1) Carrier dan adjustable strap, (2) Raincover, (3) Wadah raincover, (4) Kantong untuk masing-masing peralatan praktikum pribadi, (5) Tas jas lab, (6) Hardpouch, (7) Wadah badge nama

Dalam merancang produk, analisis ergonomi diperlukan agar produk yang dibuat 
Dita Andansari, Nur Maulida Agusnar, Desain Sarana Bawa Dan Penyimpanan Peralatan Praktikum Pribadi Bagi Mahasiswa Jurusan Teknik Kimia Politeknik Negeri Samarinda

aman dan nyaman untuk digunakan oleh pengguna. Pada perancangan produk ini, berikut beberapa analisa yang perlu diperhatikan :

1. Agar sarana bawa aman dan nyaman digunakan diperlukan batas angkat.

Batas angkat maksismal yang digunakan adalah batas angkat maksimal wanita dewasa agar produk juga dapat mencakup keamanan dan kenyamanan prngguna laki-laki dewasa. Batas angkat maksimal wanita dewasa adalah $16 \mathrm{~kg}$. jadi, berat total produk dan isi tidak boleh melampaui $16 \mathrm{~kg}$.

2. Sarana bawa yang diperuntukan bagi peralatan praktikum ini memiliki kantongkantong khusus peralatan yang disesuaikan dengan jenis masing-masing peralatan agar peralatan tidak mudah rusak.

3. Tas dilengkapi tali panjang untuk selempang bahu yang adjustable (dapat dipanjang pendekkan sesuai dengan dimensi tubuh pengguna)

Berikut hasil analisis anthropometri pada produk ini, yaitu:

1. Menentukan ukuran bukaan kantong. Dimensi tubuh yang digunakan adalah tebal tangan. Gender yang digunakan adalah pria $95 \%$ agar dapat mengakomodir ukuran pengguna secara universal. Tebal tangan pria $95 \%=$ ukuran bukaan kantong minimal $=4,7 \mathrm{~cm}$

2. Menentukan ukuran tali selempang (adjustable). Dimensi tubuh yang digunakan adalah tinggi bahu. Gender yang digunakan adalah wanita 5\%tile dengan tujuan ukuran yang digunakan dapat mengakomodir ukuran secara universal. Tinggi bahu wanita 5\%tile = panjang minimal tali selempang adjustable $=118,4 \mathrm{~cm}$

3. Menentukan ukuran handle genggam. Dimensi yang digunakan adalah lebar telapak tangan dan diameter genggam. Gender yang digunakan adalah pria 95\%tile untuk dimensi lebar telapak tangan dan wanita 5\%tile untuk diameter genggam maksimal. Hal ini bertujuan agar handle dapat sesuai dengan dimensi tubuh manusia secara universal. Lebar telapak tangan pria 95\%tile = lebar handle minimal $=8,8 \mathrm{~cm}$

Analisis konfigurasikan untuk menentukan peletakkan yang tepat bagi peralatan praktikum yang akan dibawa dengan sarana bawa ini. Adapun komponen yang ada produk sarana bawa adalah : (1) Tempat tisu, (2) Tempat lap kering, (3) Tempat jas lab, (4) Tempat masker, (5) Tempat sarung tangan, (6) Tempat kaca mata, (7) Tempat lap basah, (9) tempat sabun cuci botol, (10) Tempat sikat tabung, (11) Tempat pipet, (12) Kantong berkas, (13) Tempat alat tulis, (14) Kantong rain cover. Gambar 1 ini merupakan salah satu konfigurasi penataan komponen di dalamnya. 


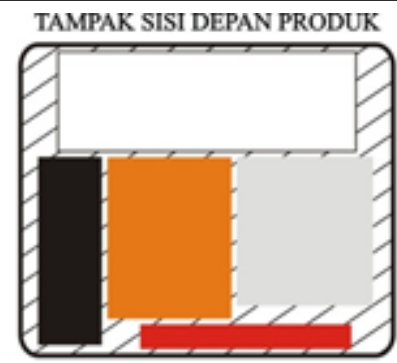

TAMPAK SISI BAWAH/BELAKANG

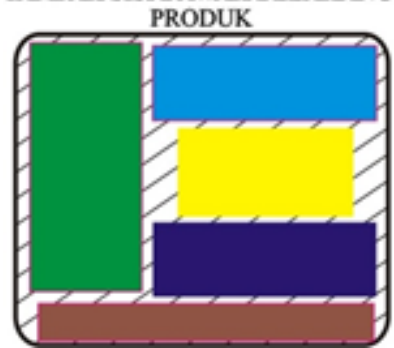

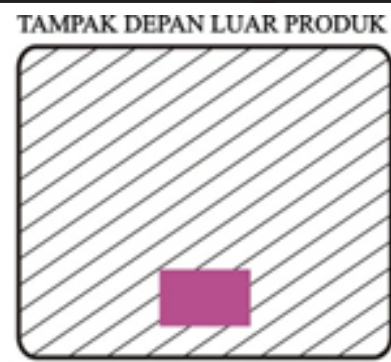

TAMPAK BELAKANG PRODUK

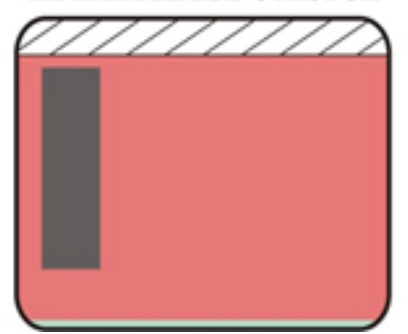

Gambar 1. Konfigurasi

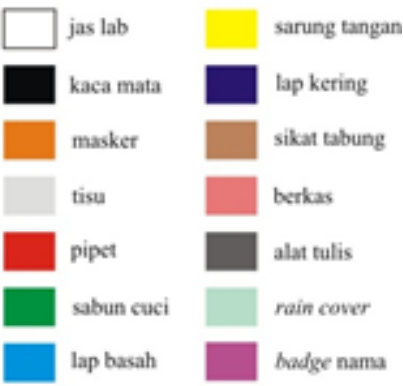

Dalam pembuatannya, tas menggunakan beberapa sistem guna menunjang pengoperasiannya, yaitu:

1. Sistem Buka Tutup. Sistem untuk bagian buka tutup produk menggunakan resleting berbahan plastik (plastic zipper), penggunaan zipper jenis ini disesuaikan dengan aktivitas membuka kantong utama produk yang membutuhkan keringkasan. Jenis plastic zipper yang digunakan adalah zipper dengan double slider, yaitu resleting yang memiliki dua arah bukaan (ke kiri dan ke kanan). Jenis zipper ini dipilih demi mendukung produk yang dirancang sebagai produk ringkas. Double slider ini memungkinkan kesingkatan waktu dalam membuka produk. Sedangkan pada bagian kantong tambahan (untuk rain cover dan berkas) digunakan plastic zipper single slider yaitu resleting satu arah.
2. Selain pada bagian bukaan produk, terdapat sistem bukaan pada penutup sekat-sekat. Bukaan tersebut akan dikunci menggunakan hook and loop tape guna meringkas waktu dalam melakukan kegiatan membuka dan menutup bagian penutup sekat penyimpanan peralatan praktikum.

3. Sistem Sambungan. Produk menggunakan sistem sambungan berupa jahitan. Jenis jahitan yang digunakan adalah jahitan kunci yang merupakan jenis jahitan yang paling umum digunakan. Jenis jahitan kunci diaplikasikan karena jenis jahitan ini kuat untuk bahan tebal seperti yang diterapkan pada produk yaitu bahan kulit sintetis yang dilapis parasut pada bagian dalamnya. Selain jenis kunci, digunakan pula jenis jahitan superimposed (tumpang) di setiap bagian pola produk yang terdiri dari 3 lapisan (kulit sintetis pada bagian luar, yellow board bagian 
Dita Andansari, Nur Maulida Agusnar, Desain Sarana Bawa Dan Penyimpanan Peralatan Praktikum Pribadi Bagi Mahasiswa Jurusan Teknik Kimia Politeknik Negeri Samarinda

dalam, dan parasut sebagai lapisan dalam), jenis jahitan ini sangat sesuai untuk diterapkan karena jenis jahitan ini diperuntukkan bagi 2 lapis atau lebih bahan. Sedangkan pada bagian sisi sisi (pinggiran) kantong ataupun pola, jahitan dibuat terlihat sehingga jenis jahitan yang diaplikasikan adalah jenis bound (terikat) karena hasil jahitan bound terlihat rapi. Jenis jahitan bound dilakukan dengan cara menghubungkan kain penyambung di atas pinggiran kain yang ingin dihubungkan satu sama lain. Selain itu terdapat pula sambungan antara produk dengan tali selempang, sambungan yang digunakan adalah gesper logam berupa kaitan sehingga tali selempang dapat dilepas saat tidak digunakan.

4. Sistem Kuncian. Sistem kuncian yang digunakan terdapat pada tali selempang agar bisa adjustable. Kuncian yang digunakan berupa ledderlock buckles yang berfungsi untuk menghubungkan 2 tali selempang yang terpisah dan memanjang-pendekan tali selempang sesuai dimensi pengguna. Terdapat pula sistem kuncian khusus pada kantong untuk pipet yang menggunakan lapisan busa EVA yang bertujuan untuk mengunci pipet saat disimpan didalam produk agar pipet tidak terbentur peralatan lain sehingga tidak mudah rusak.

5. Sistem Peletakan. Sistem peletakan peralatan praktikum pada produk adalah dengan cara diletakkan pada sekat-sekat yang telah disesuaikan dengan masing masing peralatan.
6. Sistem Bawa. Terdapat 2 sistem dalam membawa produk ini, yaitu dengan dijinjing dan diselempangkan pada bahu. Untuk mendukung sistem bawa dengan cara dijinjing, produk dilengkapi dengan carrier pendek pada bagian atas produk. Sedangkan untuk cara selempang, produk dilengkapi dengan tali adjustable yang menyilang pada sisi kanan dan kiri produk.

Untuk material yang digunakan pada produk, dipakai material yang sesuai untuk diaplikasikan pada produk yang akan dibuat. Kebutuhan produk yang akan dibuat adalah produk harus tahan akan air, kuat, mudah dibersihkan, aman bagi peralatan praktikum pribadi, serta mampu menimbulkan kesan profesional. Berdasarkan kebutuhan dan pendekatan material yang telah dilakukan maka material yang sesuai untuk di aplikasikan pada produk adalah sebagai berikut :

1. Kulit Sintetis. Kulit sintetis digunakan sebagai material utama untuk bagian luar produk. Pada dasarnya, kulit sisntetis dan polyester cordura merupakan jenis kain yang tahan terhadap air, namun kulit sintetis tidak memiliki pori-pori yang memungkinkan air sama sekali tidak dapat untuk meresap ke bagian dalam produk. Keunggulan lainnya yang terdapat pada kulit sisntetis yaitu mudah dibersihkan dan memiliki berbagai tekstur yang mampu menimbulkan kesan formal dan serius. . 
Vol. 2, No. 2, April 2015

2. Parasut. Parasut digunakan sebagai kain pelapis bagian dalam produk. Kain parasut dipilih karena kain parasut merupakan kain kedap air, mudah dibersihkan dan cepat kering yang sangat sesuai untuk lapisan dalam produk yang akan menyimpan peralatan yang memiliki kemungkinan untuk kotor dan basah. Selain untuk pelapis dalam produk, kain parasut juga di aplikasikan pada tas khusus jas lab. Kain parasut yang digunakan untuk tas jas lab adalah kain parasut yang lebih tebal sehingga tingkat kedap air nya lebih tinggi.

3. Busa Polyfoam. Busa polyfoam digunakan sebagai pelapis bagian dalam produk yang bertujuan untuk mempertahankan bentuk luar produk dan memberikan perlindungan pada peralatan didalam produk. Selain sebagai lapisan untuk mempertahankan bentuk, busa polyfoam juga digunakan sebagi penahan pada kantong sekat pada bagian dalam produk guna melindungi peralatan yang di simpan di dalamnya. Busa polyfoam digunakan karena busa jenis ini lebih mudah untuk dijahit. Untuk membuat lapisan produk serta sekat tetap kokoh, busa ditambahkan lapisan karton yellow board.

4. Webbing Tape. Digunakan sebagai penutup kantong serta bagian penutup kantong dan juga sebagai tali penghubung rain cover pada produk.

Pemilihan konsep bentuk diperlukan dalam menentukan bentuk yang sesuai yang akanditerapkan pada produk. Pendekatan yang akan dilakuakan adalah berdasarkan jenis tas dan gaya desain. Berdasarkan hasil analisis yang telah dilakukan, pendekatan jenis tas yang dipilih untuk diterapkan pada produk adalah tas jenis briefcase. Jenis tas ini dipilih karena jenis tas ini memiliki kesan yang profesional dari segi bentuknya yang simple dan kegunaan awalnya yaitu sebagai tas kerja. Bentuk briefcase akan dimodifikasi pada bagian celah. Celah tas akan dibuat lebih besar mengikuti dimensi peralatan yang akan dibawa. Berdasarkan pendekatan yang telah dianalisis, gaya desain yang sesuai untuk diaplikasikan pada produk adalah gaya desain modern vintage karena gaya desain ini merupakan perpaduan gaya modern dan vintage. Gaya modern yang simple dapat mendukung dalam sisi fungsional karena tidak ada ornamen yang dapat mengurangi efektifitas penggunaan produk. Sedangkan gaya vintage yang sangat khas dengan bahan klasik seperti kulit sangat mendukung dalam segi styling, bahan kulit memiliki kesan eksklusif dan mampu menimbulkan kesan profesional yang classy. Sehingga penerapan gaya desain modern vintage pada produk dapat memenuhi kebutuhan dalam segi styling maupun fungsi dan operasionalnya.

Grafis diterapkan pada logo yang terdapat pada leather patch. Grafis pada logo tersebut diadaptasi dari bentuk polimer Benzene yang merupakan salah satu ikatan polimer yang umum digunakan dalam aktivitas kimia. Grafis ini ditujukan sebagai penunjuk identitas kimia pada produk sarana bawa peralatan praktikum kimia ini. 
Dita Andansari, Nur Maulida Agusnar, Desain Sarana Bawa Dan Penyimpanan Peralatan Praktikum Pribadi Bagi Mahasiswa Jurusan Teknik Kimia Politeknik Negeri Samarinda

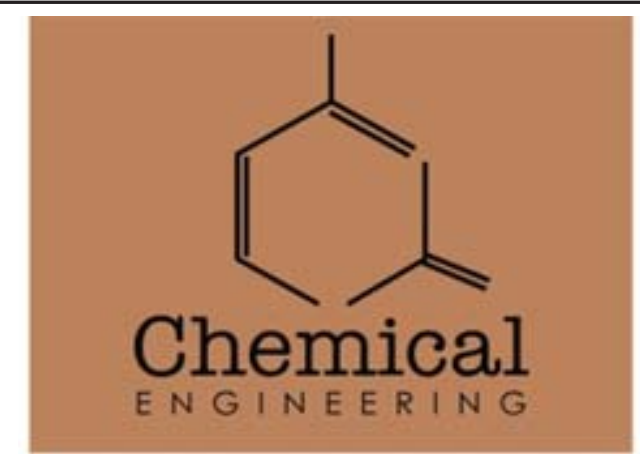

Gambar 2. Logo pada Leather Patch

Berdasarkan analisis warna yang dilakukan, warna yang sesuai untuk diterapkan pada produk adalah warna hitam dan hijau kekuningan (hijau stabilo). Warna hitam dipilih sebagai warna dominan karena warna hitam berkesan profesional serta tidak mudah kotor, warna hitam juga bersifat netral sehingga bersifat umum untuk gender pengguna. Warna hijau kekuningan dipilih sebagai warna kontras dan diterapkan pada aksen karena warna hijau kekuningan merupakan warna identitas dari jurusan teknik kimia Politeknik Negeri Samarinda yang terdapat pada logo Jurusan dan diadaptasi dari warna almamater POLNES, warna hijau kekuningan mampu memberikan kesan yang cenderung modern dan sangat mampu menyeimbangkan warna hitam yang dominan, selain itu warna ini juga mampu memberikan kesan rileks yang sangat sesuai dengan kegiatan praktikum yang membutuhkan ketenangan.

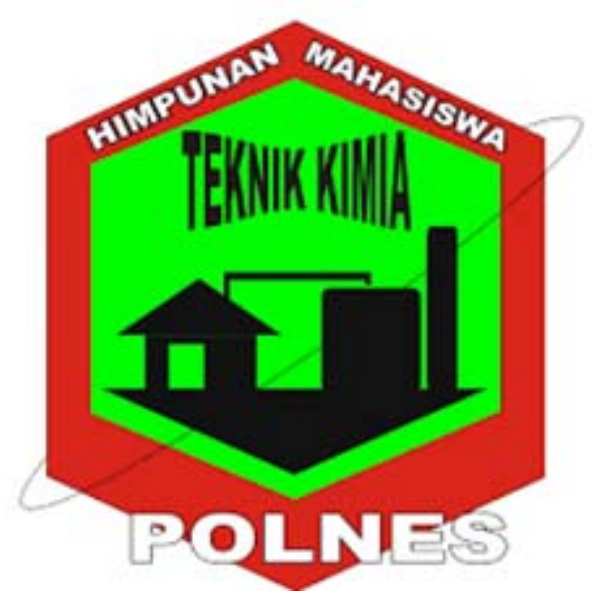

Gambar 3. Warna Logo Teknik Kimia POLNES



Gambar 4. Alternatif Desain terpilih

Langkah awal mendesain adalah membuat sketsa awal desain yang terdiri dari beberapa alternatif disertai dengan penjelasan-penjelasan. Selanjutnya berdasarkan analisis yang telah dilakukan , maka alternatif desain yang terpilih adalah alternatif desain yang ditunjukkan dalam gambar 4. Alternatif terpilih ini dikembangkan lagi menjadi beberapa desain lagi, selanjutnya dianalisis agar didapatkan hasil yang sesuai konsep dan hasil yang diinginkan. Hasil pertimbangan tersebut menghasilkan desain final yang ditunjukkan dalam gambar 5 . 


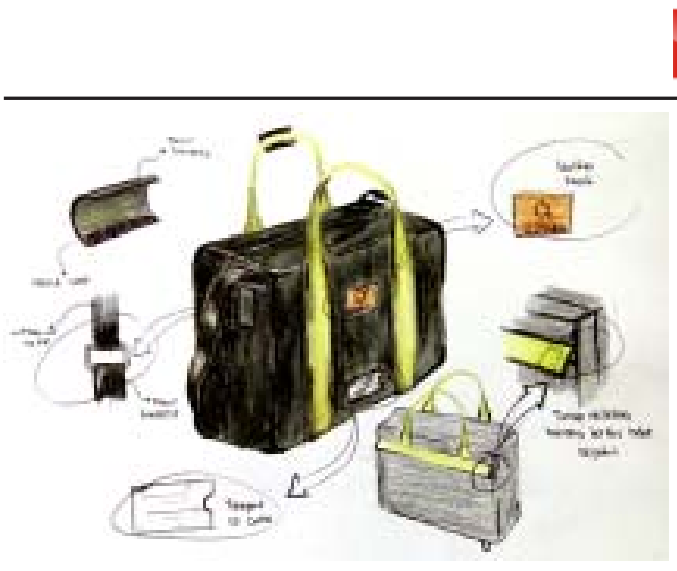

Gambar 5. Pengembangan desain teripilih

Vol. 2, No. 2, April 2015

Desain terpilih ini selanjutnya dijabarkan menjadi gambar kerja agar bisa diproduksi. Sebelum final, dibuat dulu model skala atau studi model, untuk studi kelayakan sebelum hasil desain diproduksi. Setelah hasil model studi Gambar kerja tersebut meliputi gambar presentasi, gambar isometri, gambar tampak, gambar potongan, gambar detail, gambar urai, modelling dan animasi. Gambar kerja dibuat sesuai standar baku, yang selanjutnya diproduksi prototipe nay untuk dikembangkan menjadi produk massal operasional.

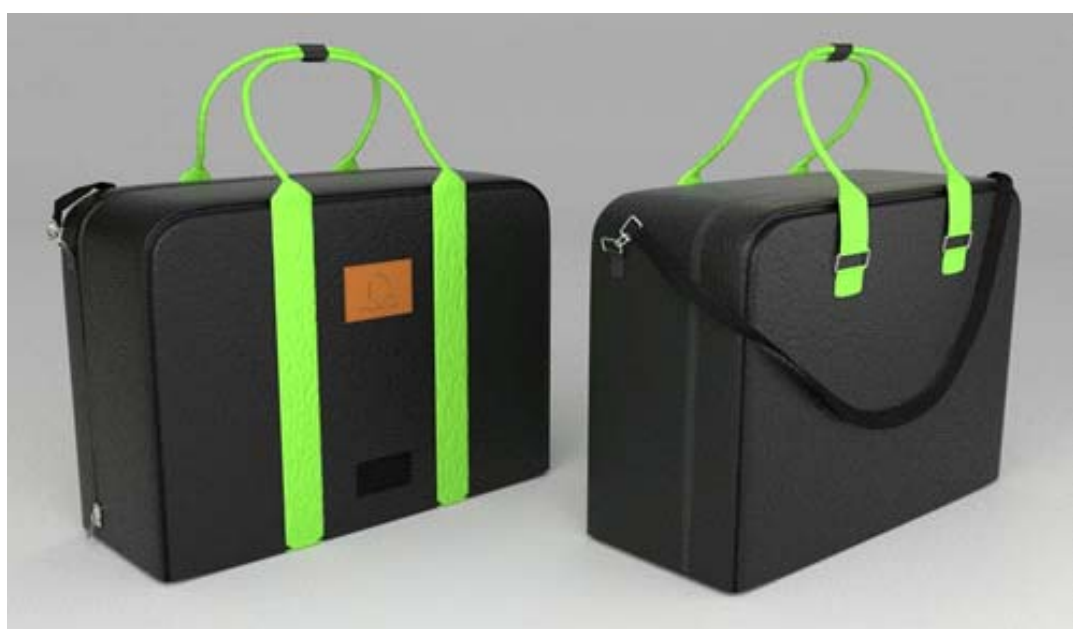

Gambar 6. Modeling produk

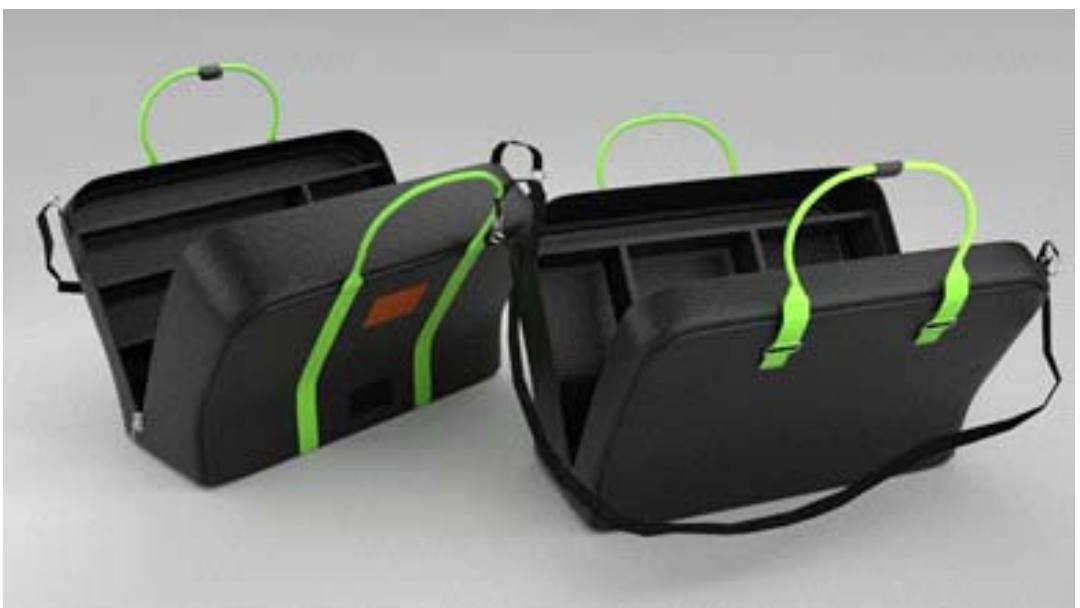

Gambar 7. Modelling produk buka 
Dita Andansari, Nur Maulida Agusnar, Desain Sarana Bawa Dan Penyimpanan Peralatan Praktikum Pribadi Bagi Mahasiswa Jurusan Teknik Kimia Politeknik Negeri Samarinda

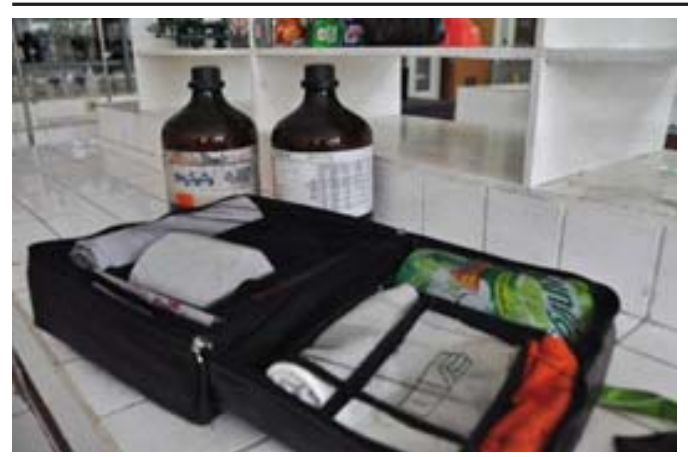

Gambar 8. Operaional produk

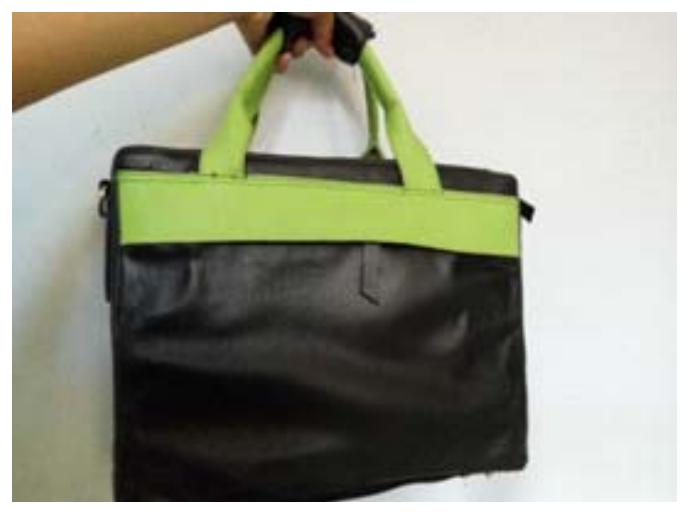

Gambar 9. Operasional produk

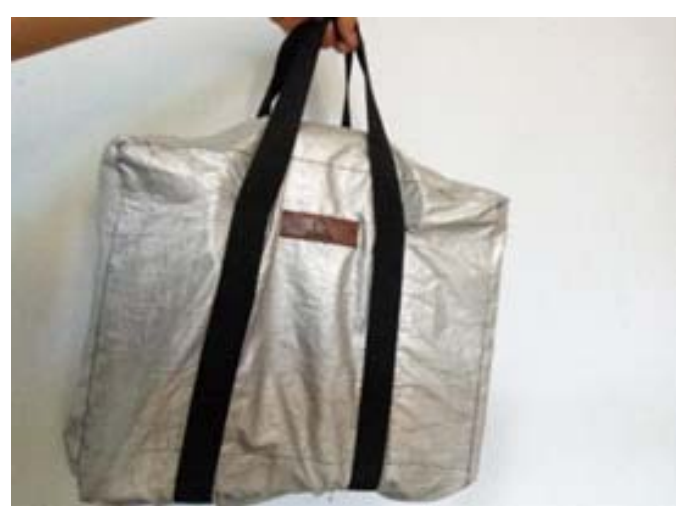

Gambar 10. Operasional produk dengan mantel tas

\section{Kesimpulan}

Berdasarkan hasil dari "Desain Sarana Bawa dan Penyimpanan Peralatan Praktikum Pribadi Bagi Mahasiswa Jurusan Teknik Kimia Politeknik Negeri Samarinda”, dapat disimpulkan Produk yang dirancang telah mampu mengkonfigurasikan peralatan praktikum secara rapid an teratur sehingga mampu memudahkan proses pemeriksaan oleh analis. Produk memiliki wadah-wadah untuk setiap peralatan yang telah disesuaikan sehingga peralatan yang fragile lebih aman dan tidak mudah rusak. Produk yang dibuat telah dilengkapi dengan carrier dan tali selempang adjustable serta telah dirancang dan disesuaikan dengan anthropometri pengguna sehingga produk nyaman untuk digunakan. Produk yang dibuat telah mencapai kebutuhan styling dalam segi bahan, bentuk serta warna yang diaplikasikan.

Saran yang dapat diberikan adalah sebaiknya mahasiswa jurusan Teknik Kimia Politeknik Negeri Samarinda memiliki fasilitas khusus untuk peralatan praktikum yang rutin digunakan dalam kegiatan praktikum yang mendukung proses belajar mengajar dan apabila produk yang dirancang akan diproduksi secara massal maka terdapat bagian yang memiliki kemungkinan untuk dikembangkangkan agar produk dapat lebih maksimal yaitu pada bagian sistem buka tutup, sekat-sekat bagian dalam produk, serta konfigurasi. 


\section{DAFTAR RUJUKAN}

Fibriani, Etwin. 2014. Modul Ergonomi hal 2-37. Politeknik Negeri Samarinda. Samarinda.

Ignacia. "Vintage dan Retro Masa Kini”. 24 November 2015. http:// www.kompasiana.com.

Kamus Besar Bahasa Indonesia Online, Badan Pengembangan dan Pembinaan Bahasa, Kemdikbud. 29 Februari, 2016. https://kbbi.web.id.

Pujiriyanto. 2005. Desain Grafis Komputer, Teori Grafis Komputer. Yogyakarta. Andi. Riadi, Muchlisin. “Teori Segmentasi Pasar”. 24 November 2015. http:// www.kajianpustaka.com/2012/11/teori-segmentasi-pasar.html.

Sari, Yuliana. 2015. Desain Tas Perlengkapan Instruktur Jilbab Untuk Komunitas Hijab Modern. Laporan Tugas Akhir pada Jurusan Desain Produk Politeknik Negeri Samarinda.

Zaeniah, Suci. M.U. 2015. Perancangan Sarana Penyimpanan Peralatan Membatik. Laporan Tugas Akhir pada Jurusan Desain Produk Politeknik Negeri Samarinda. 